\title{
RICH depuis la lettre
}

\author{
Derek Roebuck
}

Received: 14 August 2011 /Revised: 27 October 2011 / Accepted: 1 November 2011 /Published online: 30 December 2011

(C) Springer-Verlag 2011

It has been recognised for at least 15 years that there is a category of soft-tissue haemangiomas that are fully grown at birth and involute rapidly without treatment [1]. The diagnostic term "rapidly involuting congenital haemangioma" $\left(\mathrm{RICH}^{1}\right)$ was first used 9 years ago [2], at which time it was known that this lesion occurs in the liver [3].

Two papers published in Pediatric Radiology cast further light on the important entity of hepatic RICH. First, FranchiAbella and her colleagues [4] show that many, but not all, antenatally diagnosed liver haemangiomas behave like RICH. In a second paper, my colleagues and I demonstrate the imaging features of biopsy-proven hepatic RICH [5]. We also show in a literature review that many of the cases published as solitary hepatic infantile haemangioma (often called haemangioendothelioma) were almost certainly actually $\mathrm{RICH}$. That some of these patients with RICH avant la lettre ${ }^{2}$ were in retrospect treated inappropriately is completely understandable.

What should we make of the observation that patients with RICH are apparently still being treated with hepatic artery ligation [6], resection [7-9] and even transplantation [10]? Why do these reports not recognise RICH as an entity, long after its description in the literature (depuis la lettre)?

\footnotetext{
${ }^{1}$ In English, the acronym RICH is usually pronounced riche in acknowledgement of the pioneering work of our francophone colleagues in this field. Most English speakers do not adopt a fully French pronunciation, however, because using a guttural rhotic for $/ \mathrm{r} /$ makes them sound unacceptably pretentious. Luckily for us, French speakers themselves are somewhat inconsistent in their pronunciation of this phoneme.

${ }^{2}$ A French expression meaning "before it was described" (literally "before the letter").

D. Roebuck $(\bowtie)$

Department of Radiology,

Great Ormond Street Hospital for Children,

Great Ormond Street,

London WC1N 3JH, UK

e-mail: roebud@gosh.nhs.uk
}

I think the main reason is that the doctors who look after babies with liver tumours, mostly paediatric hepatologists, liver surgeons, neonatal intensive care specialists and paediatric oncologists, are disconnected from the experts in vascular tumours, who are mostly dermatologists, radiologists and specialists in numerous other fields with an interest in vascular anomalies.

Children with symptomatic hepatic RICH should be treated with aggressive supportive therapy, with embolisation reserved for those who develop uncontrollable cardiac failure $[5,11]$. Corticosteroid therapy has not been shown to be beneficial in RICH, and may cause serious complications [4]. Resection of half of a baby's liver or transplantation is rarely appropriate for this self-limiting condition, may cause fatal complications $[7,10]$ and should be regarded as a last resort when all other treatments, including embolisation, have failed [12-14]. (This overtreatment of RICH of the liver is nicely described by the French proverb le médecin est plus à craindre que la maladie. ${ }^{3}$ )

In these circumstances, the role of paediatric radiologists in diagnosing hepatic RICH and helping other clinicians reach the appropriate management plan may be critical. The radiologist may be the only member of the multidisciplinary team (or tumour board) who is familiar with this condition, and should not be afraid to speak out in the interests of the child.

Remember, for most babies with RICH l'art de la médecine consiste en amusant le patient tandis que la nature traite la maladie. ${ }^{4}$

\footnotetext{
${ }^{3}$ Literally translated, this means "the doctor is to be feared more than the illness"; in English, we might say "the cure is worse than the disease."

${ }^{4}$ This aphorism comes from Voltaire (François-Marie Arouet, 1694 1778) and may be translated as "the art of medicine consists of distracting the patient while nature treats the disease."
} 


\section{References}

1. Martinez-Perez D, Fein NA, Boon LM et al (1995) Not all hemangiomas look like strawberries: uncommon presentations of the most common tumor of infancy. Pediatr Dermatol 12:1-6

2. Berenguer B, Mulliken JB, Enjolras O et al (2003) Rapidly involuting congenital hemangioma: clinical and histopathologic features. Pediatr Dev Pathol 6:495-510

3. Paltiel HL, Burrows PE, Kozakewich HP et al (2004) Solitary infantile liver hemangioma: a distinct clinicopathologic entity [abstract]. Pediatr Radiol 34:S37

4. Franchi-Abella S, Gorincour G, Avni F et al (2012) Hepatic haemangioma - prenatal imaging findings, complications and perinatal outcome in a case series. Pediatr Radiol 42. doi:10.1007/ s00247-011-2214-0

5. Roebuck DJ, Sebire NJ, Lehmann ED et al (2012) Rapidlyinvoluting congenital haemangioma (RICH) of the liver. Pediatr Radiol 42 (in press)

6. Makin E, Davenport M (2010) Fetal and neonatal liver tumours. Early Hum Dev 86:637-642

7. Moon SB, Kwon HJ, Park KW et al (2009) Clinical experience with infantile hepatic hemangioendothelioma. World J Surg 33:597-602
8. Zhang Z, Chen HJ, Yang WJ et al (2010) Infantile hepatic hemangioendothelioma: a clinicopathologic study in a Chinese population. World J Gastroenterol 16:4549-4557

9. Kim TJ, Lee YS, Song YS et al (2010) Infantile hemangioendothelioma with elevated serum alpha fetoprotein: report of 2 cases with immunohistochemical analysis. Hum Pathol 41:763-767

10. Grabhorn E, Richter A, Fischer L et al (2009) Neonates with severe infantile hepatic hemangioendothelioma: limitations of liver transplantation. Pediatr Transplant 13:560-564

11. Dickie B, Dasgupta R, Nair R et al (2009) Spectrum of hepatic hemangiomas: management and outcome. J Pediatr Surg 44:125133

12. Draper H, Diamond IR, Temple M et al (2008) Multimodal management of endangering hepatic hemangioma: impact on transplant avoidance: a descriptive case series. J Pediatr Surg 43:120-125, discussion 126

13. Zenzen W, Perez-Atayde AR, Elisofon SA et al (2009) Hepatic failure in a rapidly involuting congenital hemangioma of the liver: failure of embolotherapy. Pediatr Radiol 39:1118-1123

14. Markiewicz-Kijewska M, Kasprzyk W, Broniszczak D et al (2009) Hemodynamic failure as an indication to urgent liver transplantation in infants with giant hepatic hemangiomas or vascular malformations - report of four cases. Pediatr Transplant 13:906-912 